\title{
BMJ Open 'Too male, too pale, too stale': a qualitative exploration of student experiences of gender bias within medical education
}

\author{
Megan E L Brown (D) , George E G Hunt (D) , Ffion Hughes, Gabrielle M Finn
}

To cite: Brown MEL, Hunt GEG, Hughes F, et al.

'Too male, too pale, too stale': a qualitative exploration of student experiences of gender bias within medical education. BMJ Open 2020;10:e039092. doi:10.1136/ bmjopen-2020-039092

- Prepublication history for this paper is available online. To view these files, please visit the journal online (http://dx.doi. org/10.1136/bmjopen-2020039092).

Received 06 April 2020

Revised 04 July 2020

Accepted 08 July 2020
D) Check for updates

(c) Author(s) (or their employer(s)) 2020. Re-use permitted under CC BY-NC. No commercial re-use. See rights and permissions. Published by BMJ.

Health Professions Education Unit, Hull York Medical School, York, UK

Correspondence to Dr Megan E L Brown; hymb2@hyms.ac.uk

\section{ABSTRACT}

Objective To explore medical student perceptions and experiences of gender bias within medical education.

Setting Gender bias-'prejudiced actions or thoughts based on the perception that women are not equal to men'-is a widespread issue. Within medicine, the pay gap, under-representation of women in senior roles and sexual harassment are among the most concerning issues demonstrating its presence and impact. While research investigating experiences of clinicians is gaining traction, investigation of medical students' experiences is lacking. This qualitative study analyses medical students' experiences of gender bias within their education to discern any patterns to this bias. Illuminating the current state of medical education gender bias will hopefully highlight areas in which student experience could be improved. Constructivist thematic analysis was used to analyse data, informed by William's patterns of gender bias, intersectional feminism and communities of practice theory.

Participants Thirty-two medical students from multiple UK medical schools participated in individual interviews. Nine faculty members were also interviewed to triangulate data.

Results Gender bias has an overt presence during medical student education, manifesting in line with William's patterns of bias, impacting career aspirations. Physical environments serve to manifest organisational values, sending implicit messages regarding who is most welcome-currently, this imagery remains 'too male, too pale...too stale'. Existing gender initiatives require careful scrutiny, as this work identifies the superficial application of positive action, and a failure to affect meaningful change.

Conclusions Despite progress having been made regarding overt gender discrimination, implicit bias persists, with existing positive action inadequate in promoting the advancement of women. Institutions should mandate participation in implicit bias education programmes for all staff and must strive to revise the imagery within physical environments to better represent society. Gender initiatives, like Athena Scientific Women's Academic Network, also require large-scale evaluation regarding their impact, which this work found to be lacking.

\section{Strengths and limitations of this study}

- This article offers an in-depth exploration of gender bias within medical education, building on previous research to demonstrate the presence of gender bias, and the patterns through which it manifests in medical students' experiences.

- This study has a large, multi-institutional, welltriangulated qualitative data set.

- A qualitative, constructivist approach has generated detailed data, well situated within gender bias theory from adjacent fields.

- To the authors' best knowledge, this is the first UK research demonstrating how physical environments within medical institutions can propagate gender bias, demonstrating transferability of early empirical work from the USA.

- There is a predominance of participants from one of the five institutions represented, given access to local study populations for sampling, which may limit result transferability to other institutional settings.

\section{INTRODUCTION}

The European Institute for Gender Equality defines gender bias as "prejudiced actions or thoughts based on the gender-based perception that women are not equal to men ${ }^{1}$-an enduring issue within medicine. As women become more equally represented within the UK's medical workforce, barriers to progression have become increasingly clear. ${ }^{2}$ Far from unique to medicine, professions such as teaching or law have undergone similar demographic changes and present evidence suggesting that such workforce changes may be accompanied by decline in the esteem in which the profession is held. ${ }^{2-4}$ This is often coupled with a reduction in remuneration, best evidenced by the gender pay gap. ${ }^{45}$ Within the National Health Service (NHS), despite women representing $44 \%$ of all doctors, $57 \%$ of medical school entrants and $89 \%$ of nursing staff, ${ }^{6}$ a notable pay gap exists; $92 \%$ of NHS trusts reported a pay 
gap in favour of men as of $2018,{ }^{7}$ with little progress by 2019. ${ }^{8}$ Given research linking staff 'believing (their trust) provides equal opportunities for career progression' and patients' positive experiences of care, ${ }^{9}$ striving for gender equity is crucial. Nonetheless, inequality persists and the picture within medical schools is no more encouraging. Female medical students experience sexual harassment at far higher rates than those enrolled on non-medical undergraduate degrees, ${ }^{10-12}$ and $58 \%$ of female medical faculty also report experiencing sexual harassment. ${ }^{13}$ Furthermore, women are poorly represented within both academic medicine ${ }^{14}$ and senior medical school faculty positions, ${ }^{15}$ decreasing their visibility within medical schools.

Growing concerns regarding gender bias within higher education led to the establishment of the Athena Scientific Women's Academic Network (SWAN) charter in 2005 to encourage and recognise commitment to advancing the careers of women. ${ }^{16}{ }^{17}$ Membership is stratified into three awards (bronze, silver and gold), which encourage universities to adopt strategies for female advancement. It is thought Athena SWAN incentivises institutions to make changes necessary to improve prospects of female staff and influence cultural transformation through its 'contextually embedded systematic approach' ${ }^{18}$ Educational institutions are widely engaged with Athena SWAN, yet recent evidence published in a report commissioned by Advance Higher Education 'The Future of Athena SWAN' casts doubt on its utility. ${ }^{19}$ Published March 2020, the report highlights the fact that $48 \%$ of respondents in a UK sector survey of 1578 faculty reported they were not confident in the consistency of the assessment process, with bias from some panel members a key concern. ${ }^{19}$ Despite recent interest in the charter's application, empirical research on the charter's influence on educational culture, particularly within medical schools, is lacking.

Although gender bias within UK medical education has been traditionally most frequently explored from the perspective of clinicians or academics, ${ }^{20}$ research which investigates the experiences of medical students is increasingly commonplace. In 2005, Stratton et al conducted an in-depth analysis of student bias experiences within medical education in the USA, demonstrating how gender bias can influence specialty decisions. ${ }^{21}$ In 2006 , Witte $e t$ $a l$ reported that medical students experience gender bias in regard to learning opportunities, although men more frequently reported gender as a barrier to their clinical education. ${ }^{22}$ More recently, scholars have reported student 'acculturation to unprofessional behaviour' within medical education, ${ }^{23}$ which is gendered in nature and desensitises students in accepting gender bias within healthcare. The bias experienced by preclinical medical students was reported by Babaria et al to be both subtle and overt in nature, with emotional and educational consequences for the students on the receiving end of this prejudice. ${ }^{24}$ Shaw et al reported students' experiences of professionalism dilemmas within hospital settings in Sri Lanka, highlighting how gender bias has lasting impact on students' professionalism development, and calling for further exploration of gender bias within medical education to add breadth and depth to this emerging direction of research. ${ }^{25}$ The recent paper by Samuriwo et al has begun to answer this call, demonstrating how gender influences how students are taught and supported within clinical practice. ${ }^{26}$ Samuriwo et al suggest gendered apprenticeship theory and the notion of gendered communities of practice may provide an explanation as to how gender bias is internalised, accounting for some of the challenges female students face when attempting to access support and mentorship. ${ }^{26}$ However, conceptualisations of gender bias within medical education are still relatively nascent, and there has been little focus on discerning the patterns of gender bias students experience. Further to this, there has been a recent call for medical education research to apply feminist theory to issues of gender bias to appropriately identify and confront areas of inequality, ${ }^{27}$ which remains unanswered.

Research concerning gender bias has been criticised by some for adopting overly theoretical stances, instead of focusing on the praxis of influencing change and promoting action within medical schools. ${ }^{28}$ Yet there is value in theorising gender bias, as clear conceptualisations of the phenomenon assist in designing interventions to improve student experiences and targeting campaigns for change..$^{29}$ Given the early status of investigating student experiences of gender bias within medical education, this research set out to investigate the manifestation of gender bias by exploring the experiences of medical students and faculty at UK medical schools, applying patterns of bias, communities of practice and intersectional feminist theory to the issues at hand. Although this work adopts a theoretical orientation, patterns of bias and communities of practice theory are associated with analyses that can improve workplace ${ }^{30}$ and educational experiences. ${ }^{31-33}$ Adopting the feminist lens of intersectionality begins to answer the call for the use of feminist theory within medical education, and conceptualises gender as a complex, fluid entity that intersects with other identities participants hold. In doing so, 'overlapping systems of discrimination, ${ }^{34}$ can become apparent, highlighting further areas in which action is necessary. Using theory (namely patterns of bias theory and intersectional analysis) that have not previously been applied specifically to the study of gender bias within medical education should also assist in developing a breadth and depth of understanding in regard to the experience of gender bias within medical students.

\section{MATERIALS AND METHODS \\ Research approach}

This work was done from a constructivist orientation. Constructivism maintains that individuals construct knowledge through social practices and interactions. ${ }^{35}$ Knowledge is created, not merely discovered by the mind. ${ }^{36}$ Within medical education, constructivism and 
constructionism are often used synonymously, yet the paradigms differ. ${ }^{37}$ While both theories highlight the subjectivity of reality and knowledge, constructivism emphasises the role of the individual in knowledge formation, while constructionism maintains knowledge and reality, are influenced by, and exist only within social interactions. ${ }^{3638}$ While constructivist research gives primacy to the perspectives of individuals, constructionist research emphasises interaction, more frequently adopting observational methods of data collection and employing methods of analysis that focus on language ${ }^{37}$ Both constructivist and constructionist approaches add value within research, and the approach adopted depends largely on the focus of a work's research question. This work adopts a constructivist orientation, conceptualising reality as a subjective, individual mental construct and emphasising knowledge construction as individual meaning-making in response to the social situations experienced by participants. Adoption of a constructivist ontology and interpretivist epistemology provides a rich perspective regarding gender bias within medical education, ${ }^{26}$ as thought is given as to how social context influences the way individuals experience and rationalise gender bias. These ontological and epistemological orientations also align with the philosophical basis of the theories selected for use within this research. Previous work demonstrating the presence of gender bias within medicine highlights patriarchal culture as a key propagator of bias ${ }^{27} 39$; our constructivist paradigm allows for greater exploration of this, through recognition that "understandings of the world are... culturally and historically situated ${ }^{40}$ and therefore subject to change. ${ }^{38}$ As we were interested in participant experience and perceptions of gender bias within medical education, constructivist thematic analysis, informed by grounded theory convention, was selected as the qualitative methodology best suited to exploring this "complex social phenomena' as it exists in the minds of participants. ${ }^{41-44}$ Constructionist investigations that attend more specifically to meaning-making within interactions would also be of value in conceptualising gender bias within medical education but fall outside the scope of this research.

Befitting our interpretivist approach, we acknowledge our own perspectives and backgrounds have inevitably influenced this study's design and analysis. ${ }^{45}$ Thus, in the interest of reflexivity, we detail our own backgrounds. MELB is a PhD student in medical education and has previously worked as a junior doctor, where she experienced gender bias firsthand. FH is a medical student, currently in her clinical years where she has professionally experienced gender bias. GEGH is also a medical student in his clinical years, who has witnessed and experienced gender bias. GMF is a professor of medical education, also involved in researching gender bias with clinical academics.

\section{Theoretical framework}

Background literature was read and used abductively, to theoretically situate findings. The sensitising concepts drawn on throughout data analysis were intersectional feminism; William's common patterns of bias; communities of practice theory and, within this, paradigmatic trajectories. A brief overview of each of these sensitising concepts is offered here .

Intersectionality is gaining pace as a concept within medical literature, particularly when discussing professional identity, ${ }^{346}$ where it is defined as 'recognis(ing) the impossibility of separating social categories such as race, class, gender, and sexuality: the multiple identities we possess should be seen as transformational rather than additional' ${ }^{46}$ In the context of feminism, intersectionality involves recognising 'multiple intersecting and interacting sources of... oppression' such as gender, race, ethnicity and sexual orientation. ${ }^{47}$ An intersectional approach to data analysis is crucial to ensure equitous advancement of research in this field-it is both befitting the constructivist orientation of this work, and highlights voices and perspectives 'largely unheard within medical education... including those of women living in poverty, women of colour, gay, lesbian and transgendered people, and Indigenous peoples'. ${ }^{27}$

Alongside recognising the intersectional nature of bias within medical education, it is important to consider the patterns of ways in which bias manifests, of which there is a paucity of medical education literature. Identification of these patterns would allow for more ready identification and management of, often subtle, biases. Williams, a professor of law and scholar researching gender bias within professional business environments, describes four patterns of bias experienced by women within the workplace. These are: tug of war; the maternal wall; tight-rope bias and prove-it-again bias. ${ }^{48}$ Descriptions of these are given in table 1.

In order to better understand the experiences of participants in this work, it is important to conceptualise the environment in which they are learning. Communities of practice theory explores the social world of medicine and medical education. Communities of practice, as defined by Lave and Wenger, are groups of people who share a common interest and interact regularly, engaging in some form of practice or learning. ${ }^{49}$ Students begin to engage with communities of practice in a process known as 'legitimate peripheral participation, ${ }^{49-51}$ where, through 'informal (learning) by social interaction, ${ }^{52}$ they become progressively more engaged, eventually acquiring 'old-timer status'. ${ }^{53}$ Within communities of practice, paradigmatic trajectories exist-visible career paths that 'shape how individuals... find meaning in their own experiences ${ }^{54}$ and model their own professional identities. ${ }^{50}$ Hill and Vaughan previously demonstrated that gender bias within paradigmatic trajectories acts to deter women from careers in surgery. ${ }^{54}$ Building on this, we consider gender bias within paradigmatic trajectories in a broader sense-does the claim by Hill et $a l$ hold true when considering medical education more generally, or is this a phenomenon unique to surgical careers? 
Table 1 Adapted table from William's work on patterns of gender bias

\begin{tabular}{ll}
$\begin{array}{l}\text { Pattern of } \\
\text { bias }\end{array}$ & Description \\
\hline $\begin{array}{l}\text { Prove-it-again! } \\
\text { Descriptive bias - stems from assumptions about the typical woman. Women have to prove themselves over } \\
\text { and over again to be seen as equally competent to men. }\end{array}$ \\
\begin{tabular}{ll} 
Tight-rope bias & $\begin{array}{l}\text { Prescriptive bias - stems from assumptions about how women should behave. Describes a double bind: } \\
\text { if women behave in traditionally feminine ways they exacerbate prove-it-again problems. If they behave in } \\
\text { masculine ways, they are seen as lacking social skills. }\end{array}$ \\
$\begin{array}{l}\text { The maternal } \\
\text { wall }\end{array}$ & $\begin{array}{l}\text { Descriptive bias - strong negative competence and commitment assumptions triggered by motherhood. } \\
\text { with children are routinely pushed to the margins of the professional world. }\end{array}$ \\
\hline Tug of war & $\begin{array}{l}\text { Occurs as women navigate own path between assimilating masculine traditions and resisting them. Women's } \\
\text { different strategies (eg, tom boy vs preserving female tradition) pit them against one another, leading to }\end{array}$ \\
judgement on the 'right way' to be a woman.
\end{tabular} \\
\hline
\end{tabular}

Bias is described as either descriptive bias (regarding what women are like), prescriptive bias (regarding how women should behave) or both.

The above-described theories were identified as key theoretical concepts underpinning gender bias and befitting a constructivist perspective. These important and theoretically robust concepts have thus far been insufficiently applied to the study of gender bias within medical education. As such, they were used as sensitising concepts to our data analysis, allowing deeper understanding of the phenomenon of gender bias within medical education.

\section{Research questions}

This study's primary research question was: how do medical students perceive gender bias within medical education? Several secondary research questions arose: is there a discernible pattern to the manifestation of gender bias within medical education? and how does gender bias influence medical students?

\section{Data collection}

Following institutional ethical approval, UK medical students at any stage and from any UK institution were invited to interview through advertisements placed and shared on social media, and by local email recruitment at one UK institution. Semi-structured, detailed, oneto-one interviews were undertaken by either GEGH or FH with consented volunteers. All interviews used open question stems to enquire after participant experiences and perceptions of gender bias within medical education. Forty-one participants were interviewed in sum, 32 students and 9 faculty. Five institutions are represented within our student sample, although one institution is most heavily represented, as the source of 23 students and all faculty. For convenience, all faculty were purposively recruited from one medium-sized, undergraduate UK medical school in the north of England. This medical school employs administrative, academic and clinical academic members of faculty. Faculty were interviewed as a way of triangulating data, permitting richer analysis. Each student participant was offered a £5 Amazon voucher as a thanks for their time. Data were collected in iterative, abductive cycles, using constant comparison alongside continual reference to existing literature. ${ }^{44}$ Audio recordings of the interviews were transcribed verbatim, re-examined for accuracy and anonymised for analysis.

\section{Patient and public involvement}

This research was done without patient involvement, as it does not directly involve patients as research subjects. Patients were not invited to comment on the study design and were not consulted to develop patient relevant outcomes or interpret the results. Patients were not invited to contribute to the writing or editing of this document for readability or accuracy.

\section{Data analysis}

A constructivist thematic analysis approach, informed by constructivist grounded theory coding conventions as detailed by Charmaz, ${ }^{55}$ was undertaken to analyse data. ${ }^{42456}$ Traditional grounded theory, as made popular by Glaser and Strauss in 1967, is a research methodology often used to investigate social processes and 'concerned with... generation of theory, which is "grounded" in data that has been systematically collected and analysed" ${ }^{57}$ Although traditional grounded theory is rooted in a positivist paradigm, assuming a 'single external truth awaits discovery', ${ }^{45}$ modern iterations of the theory have been constructivist in orientation, emphasising the subjectivity of reality and the active role research teams play in the generation of study results. ${ }^{45} 58$ Noble and Mitchell summarise the key features of constructivist grounded theory, ${ }^{57}$ which include: simultaneous data collection and analysis; the development of codes and categories grounded in study data; theoretical sampling to refine categories; inductive construction of abstract categories using constant comparison; the use of analytic memos and drawing on categories to construct the theoretical framework of a study. ${ }^{57}$ Gender bias is a complex construct, uniquely experienced by each individual that remains at an early stage of theoretical conceptualisation within medical education. As such, an approach informed 
by constructivist grounded theory, which generates data inductively from participant accounts, while situating evolving data within pre-existing background literature, should add depth to this direction of research.

In line with the recommended steps by Noble and Mitchell, participant transcripts were read multiple times, with all members of the research team subsequently independently competing line-by-line open coding of all transcripts using NVIVO V.12. Where possible, participants' own words were used to assign 'in vivo' codes to each line of a participant's transcript ${ }^{59}$ Initial open coding occurred alongside data collection in iterative cycles and using a constant comparative approach. The research team met regularly to discuss findings and undertake focused and theoretical coding, abstracting initial line-by-line coding into categories within focused coding, and scrutinising connections between codes to create themes within the 'theoretical coding' stage. ${ }^{55}$ As the study progressed, additional students were recruited in line with a theoretical sampling approach, to refine the conceptual model being generated and give a more equitable distribution of stages of training in our final sample. Memo-writing was used throughout to deepen analysis and document thoughts regarding the identification of themes within the 'theoretical coding' stage of analysis. Regular meetings were used to discuss when theoretical sufficiency (a term used in lieu of the previously popular but problematic concept "thematic saturation, ${ }^{45}$ ) had been reached and data collection could cease. ${ }^{43}{ }^{44}$ Following completion of all interviews, the research team met to discuss, debate and finalise agreed coding and themes.

\section{RESULTS}

A total of 41 participants completed the study, 32 students from multiple UK medical schools and 9 faculty members from one school. Demographic information can be viewed in table 2. In the quotes listed during this section, $\mathrm{P}$ refers to a student participant and $\mathrm{T}$ to a tutor/faculty participant.

\section{Themes}

Preliminary analysis identified 55 descriptive open codes from interview transcripts. These codes were organised into 3 major themes, 6 subthemes and the initial descriptive codes collapsed into 19 open codes, as shown in table 3 .

Table 2 Participant demographics

\begin{tabular}{|c|c|c|c|c|}
\hline \multirow[b]{2}{*}{ Gender } & \multirow[b]{2}{*}{ Age } & \multirow{2}{*}{$\begin{array}{l}\begin{array}{l}\text { Year of study } \\
\text { (students) }\end{array} \\
\begin{array}{l}\text { Occupational position } \\
\text { (faculty) }\end{array}\end{array}$} & \multirow[b]{2}{*}{ Ethnicity } & \multirow[b]{2}{*}{ Institutions } \\
\hline & & & & \\
\hline Students: & $\begin{array}{l}\text { Students: range 19-29, } \\
\text { mean } 22.4\end{array}$ & Students: & White British $=22$ & Students: \\
\hline Year 1 & Faculty: & Year $1=3$ & Black British=2 & Institution A: 5 \\
\hline Female $=2$ & $30-40=1$ & Year $3=8$ & Chinese $=1$ & Institution C: 2 \\
\hline Trans male $=1$ & $40-50=1$ & Year $4=10$ & $\begin{array}{l}\text { Any other Asian } \\
\text { background=1 }\end{array}$ & Institution D: 1 \\
\hline Year 2 & $50-60=5$ & Year $5=6$ & Indian British=1 & Institution E: 1 \\
\hline Male $=3$ & $60-70=1$ & Faculty: & White European $=2$ & Faculty: \\
\hline Male $=3$ & & Administrative: 1 & Black African=2 & \\
\hline \multicolumn{5}{|l|}{ Female $=5$} \\
\hline \multicolumn{5}{|l|}{ Year 4} \\
\hline \multicolumn{5}{|l|}{ Male $=0$} \\
\hline \multicolumn{5}{|l|}{ Female $=10$} \\
\hline \multicolumn{5}{|l|}{ Year 5} \\
\hline \multicolumn{5}{|l|}{ Male $=1$} \\
\hline \multicolumn{5}{|l|}{ Female $=5$} \\
\hline \multicolumn{5}{|l|}{ Male $=6$} \\
\hline
\end{tabular}


Table 3 Major themes, subthemes and open codes

\begin{tabular}{|c|c|c|c|}
\hline Major theme & Perceptions of a culture of bias & Organisational culture & Desired transformational change \\
\hline Subtheme 1: & Patterns of bias & Culture & Action \\
\hline \multirow[t]{2}{*}{ Open codes: } & Maternal wall bias & Sociocultural impact & Balancing the boardroom \\
\hline & Prove-it-again & Physical environments & Balance redresser \\
\hline \multirow[t]{4}{*}{ Open codes: } & Capability & Intersectional & Initiative challenges \\
\hline & Pressure & Overtly perceived & Reporting challenges \\
\hline & & Microaggressions & \\
\hline & & Structural & \\
\hline
\end{tabular}

\section{Major theme 1: perceptions of a culture of bias}

Participants discussed various ways gender bias manifested within their education experience, as they looked up to those more senior and considered their own future within this medical landscape. This experience fits with the four patterns of bias described by Williams $e t a l^{48}$ and detailed within our conceptual framework.

Tug-of-war bias manifests as women navigate a path between assimilating masculine medical traditions and resisting them in attempt to maintain their sense of self. Deviation from masculine stereotypes on clinical placement was perceived as a weakness, acting as a form of prescriptive bias.

In the clinical years, suddenly... you've got to abide by stereotypically masculine rules. You need to be large and in charge... act a certain way. Any femininity is seen as a weakness or liability. P10

In one male student participant, this bias manifested as a descriptive bias in his perception as women clinicians as more 'tick-box' than male clinicians, less willing to develop interpersonal relationships with students.

Males... are more relaxed, whereas women... are a bit more career focused and like to tick the boxes and do what they've been assigned. P26

Maternal wall bias acted prescriptively, pushing female students away from considering certain specialities. Deterrents from pursuing a surgical career and encouragement towards general practice due to assumed future maternal status, were mentioned particularly frequently. Male doctors were the main propagators of this bias, which manifests in practice as biased advice and a sense of being 'looked down on'.

People, females in our year, and myself, want to be a surgeon. And when we're asked 'what do you want to do?'... by male consultants... we want to be surgeons... and they say, 'no, you shouldn't, you're female, you should think about family'. P8
... people have said if you want to have children as a female, not to do surgery. P7

Sometimes people talk about career prospects, particularly because we work in an all-girl group, they think, 'If you're going to have kids in the future, [being a $\mathrm{GP}]$ is great'. And they do emphasise that aspect. P22

This bias also acted descriptively, triggering negative assumptions regarding a woman's competence and commitment following motherhood. This acts to disadvantage the career progression of women, a finding most evident among medical school faculty who had become mothers while working.

I lost my only position of seniority when I returned from maternity leave, as the powers that be presumed it would be too much for me. T2

It was suggested I wouldn't want promotion as I was busy with kids... presumptions that if I'm not at my desk I am with the kids, not leading a new research initiative etc. are rife. T4

In some female students, the presence of this bias dissuaded them from possession of ambitious career aspirations.

I'm much more likely to take a less involved job, just because of child bearing and stuff. P24

Tight-rope bias, stemming from assumptions about how women should behave, was also evident amongst participants. Having a family during medical school or the UK foundation programme was seen as unprofessional.

I have had tutors that have been very upset because their FY1 or FY2s haven't been able to be with them for a period of time due to being pregnant or having children...the vibe you got was, 'I'm very unhappy that she's not coming into work because she's having a child and now I am bearing the brunt of this whole horrible decision that she's made!' P27 
Women were caught in a catch-22. Behaving in stereotypically feminine ways was viewed negatively, as unscientific and unserious. Yet, behaving in stereotypically masculine ways was seen as 'un-ladylike'. Prescriptive tight-rope gender bias means women are inescapably liable to criticism.

Being too feminine is definitely a negative thing... on the wards... I had a few FY1s tell me not to wear lipstick or bold colours because the male seniors won't take you seriously. P34

You get these female surgeons and I have heard people criticise them... for their manner... saying they're unladylike... not a real woman, they had to change into a pseudo-man to pursue surgery. P30

Prove-it-again bias stems from prescriptive tight-rope bias, and assumptions made about how women should be and behave. In line with the above negative feminine assumptions, women were assumed to lack physical strength and intelligence, when compared with their male counterparts.

They automatically assumed 'oh you're not going to be interested in orthopaedics, you're not going to want to help in theatres, you've not got the strength to do it'... they get the boys much more involved P5

... assuming that you're not as clever as a male. P11

In light of these assumptions, women have to prove themselves over and over again to be viewed as equally competent.

...you've more got a point to prove... you've got to be above and beyond your male counterparts. P4

Within medical education, prove-it-again bias becomes most evident to female students in question and answer sessions.

I do think people dumb stuff down... they always act more surprised when we do well or know something better than the guys do. P7

Some students had also experienced censoring of their clinical experience by male clinicians who perceived them as less capable.

...we were being told we weren't allowed to see certain patients or procedures because of our gender. So, the boys were allowed to do it because they could handle it... the stereotype of oh he's big, he's a boy he can handle himself'. P10

Negative rhetoric regarding women's abilities and the pressure to prove-it-again were both draining and, in some cases, infectious. Although participants remained largely aware of bias, some recognised the negative impact it had on their self-perception.

If I'm constantly told only boys can do this, or I only ever see boys do this I'm gonna think 'ok maybe there is something about boys that make them better suited and I can't do this'. P10
In others, this burden was felt as a pressure to conform to traditional gender roles, as defined by the prescriptive tight-rope and maternal wall bias propagated by men.

I don't like to rock the boat... even if they make reference to family friendly specialities... so for my comfort I tend to nod and smile along... P29

\section{Major theme 2: organisational culture}

Participants described their experience of medical culture as they studied and worked within the field, looking around their own environment to draw cultural conclusions. Gender bias was seen as wide reaching and deep-seated within medical schools, the NHS and society as a whole. Given this, it was viewed as difficult to change without concurrent action regarding gender bias in a societal sense.

I think it's going to be very hard to change something that's so widely spread. I think it will just take time and take a change in society as well as within med school, and within the rest of the NHS. P18

In some, this manifested as pessimism regarding advocating for change.

There's nothing you can really do about it, it's just sort of society. P12

Within medicine, the paradigmatic trajectories provided by a community for women remain gendered. Stereotyping of students, based on historical paradigmatic trajectories of women in nursing, occurred with particular frequency.

The patient was referring to him as 'You're the doctor...' and referring to my friend, who's a girl like 'oh you must be the nurse, right?'. To be honest you get that on the ward as well, from health professionals. P11

...they would ask us, 'Are you going to be nurses?' And assume the boys were training to be doctors. We definitely had that a lot. There's been multiple occasions when patients would assume, we were training to be nurses just because we were female. P16

I think it's from a historical preference-doctors are men, nurses are female. P5

Access to paradigmatic trajectories on whom women could model their career aspirations was poor in some areas. These non-visible trajectories acted to dissuade students of their own competence regarding careers in specialities such as surgery.

If a female wants to do surgery there's not enough people they can look up to and think-I can do this. P2

When career trajectories were visible within surgery, students often viewed them as fraught for women, due 
to the possibility of encountering the patterns of bias mentioned previously.

...surgery is the most notorious for being worse for females. P14

As a result of non-visible or fraught paradigmatic trajectories for women in certain specialities, female students experienced restriction of their learning opportunities. This prevented engagement with potential specialities and trajectories of interest, further dissuading consideration of a career in such areas, and propagating a cycle of paradigmatic trajectory inequality.

I found orthopaedics quite interesting but... when

I was in theatres, I wasn't given the opportunity to scrub up and take part in anything I was potentially interested in. I suppose I'll never know if I was actually interested in it... I never got the opportunity to do the practicality of it because they'd rather have a boy scrub up, which is quite sad really. P5

In contrast to the poor representation of women in some specialities, students noted female medical school faculty provided them with paradigmatic trajectories they could emulate.

.... lot of the faculty is female... that's quite good to see as an example... P12

However, and in agreement with male and female faculty members, other students viewed women's trajectories as having hit the glass-ceiling, with men most well represented in senior institutional roles.

It is mostly women in PBL and men in lecturing.... P26

Women aren't as common in the upper echelons... that sends quite a strong message ... [that] women aren't as suited to be leading. P41

Female senior medical educators... have said to me... as females it's been more difficult for them to rise up the hierarchy at work than it would be, if they were males.... It is around, the 'glass ceiling' as they call it... T2

In as much as the culture of medicine is manifested within structural hierarchy, it is mirrored materially in physical environments. Physical art adorning the halls of medical schools and healthcare institutions was seen to embody traditional medical patriarchy and propagate implicit bias.

Everywhere you look there's imagery that subtly tells you who you should be. And that imagery is inevitably always too male, too pale and too stale. There's really not enough diversity in the images we see in the halls of medical schools, medical buildings, hospitals...we need to work harder to ensure the important contributions of women and particularly women of colour, LGBTQ+women, are recognised. Replacing some, if not all, of those old portraits is the start of that. Walls really do talk, and right now we're sending out the message that if you don't look like this, like an old white guy, then you're not welcome... P41

Functional hospital design was also viewed as malecentric, promoting gender segregation and prioritising male facilities.

...male changing rooms are in the actual theatres whereas the female changing rooms aren't, they're like attached to the ward. P7

Within educational environments, gender bias materialised physically as stereotyped male and female health attitudes within simulated patient scenarios.

There's a classic like... when you are talking to simulated patients...the ones who are saying, 'Oh, my partner has made me come' are always the men... that classic, 'Guy's don't come to the Dr unless they're desperately in need'... that's kind of something which I'd say is a stereotype constantly shown in the exams... Again...when you talk to them about worries, the men will say, 'I'm worried because of my family, if I'm out of work I won't be able to provide for my family. P30

Participants also described a lack of diversity within their medical education, both with simulated patients and clinical encounters. Students expressed frustration regarding patient diversity representing one discrete educational session, as opposed to it being an integrated and integral strand of the curriculum.

...because honestly, we haven't seen any patients that aren't white, over $40 \ldots$ it's like, 'Can we see some other people?'... I think that was one of the learning outcomes for one of the clinical skills sessions... Maybe going more into that....and not just making it one session of the course and integrating it throughout the course... you need to have that exposure from an earlier stage. P19

Lack of diversity was also noted among faculty, with women of colour highlighting the importance of diverse role models in their educational journeys.

I can remember that first time we had a black female lecturer. And that was amazing, because that was the only female, black female doctor that I'd seen in the whole year... And it makes you feel excited when you do see someone else who looks like you... And when you don't you feel, 'Do I even belong here?', and it makes you feel out of place. Sometimes in lectures you just sit there and are like-'Damn, I'm the only black person in that room'. And it's not a good feeling. P19

The bias students experienced was often intersectional in nature, with comments biased against a multitude of protected characteristics. These comments sometimes 
took the form of warnings from male clinicians regarding the risk of prove-it-again bias.

He'd say 'you can see (me) working in a nail bar'. So that's also racism/sexism. Yeah I'm a girl I don't deserve to work in a hospital... and obviously Asian people work in nail shop. P12

It's multifactorial-might be because I'm female, might be because of my race. $\mathrm{P} 8$

He would say 'you are a black woman; you have to work extra hard to get forward. You know women have it a bit harder'. P6

Institutionally, medical schools were perceived as dutybound to increase awareness regarding the possibility of intersectional bias among students, who currently felt ill-equipped to deal with inappropriate comments from patients. Tutors echoed this lack of training.

I just didn't know what to say... no one has ever really sat us down and said, "this is what to do... if patients say something like that. P41

We need to make sure that people are aware that [it is] going to happen, because that's a bigger societal issue isn't it.... It's gender, it's race, it's a whole bunch of things that a patient may react to...it's how you deal with that... T7

Alongside the experience of intersectional bias, female students also concerningly described encounters possessing inappropriate sexual overtones. Unsurprisingly, this proved distressing. Witnesses, in the form of present healthcare staff, acted as bystanders in the described instances, ignoring the presence of gendered, sexual comments. Comments originated both from patients...

...patients, usually male, saying that they're more willing to speak to us because we were all females and young... When you're in that sort of professional role... [it] puts you off, and makes you uncomfortable and makes you unable to do your job-unable to concentrate and things like that... P12

I had a patient say something inappropriate when I was doing an abdominal exam about being touched near his groin... I wouldn't necessarily expect other students to confront him... but the tutor just completely ignored what he said... that was actually quite frightening. P40

....and from staff.

I witnessed a female medical student being, first of all accused that they could see her underwear when I don't think-this was a male doctor who said he could see her underwear-when I don't think they could have done. I think he didn't need to point it out to her. He then followed it up by saying the only reason she was getting good praise by one of the male doctors was basically-it sounded like he was saying they'd slept together-and that was the only reason she was getting praised...it's saying the only reason a female could have positive feedback is because she was sleeping with a male.... also the fact he could see down her top when she was bent over, he wouldn't have mentioned it if it was a male. A lot of the guys don't do their top button up-no one mentions it. P8 I was in general surgery last year and there was a consultant who just used to say things that were quite derogatory towards women. For example, about an old man patient we had just seen. He said, 'oh yeah as we get older us blokes turn into women-your balls shrink, you grow tits and your brain shrinks too'. We all just stood there as group of three girls... feel[ing] uncomfortable. P5

Parallel to overt forms of intersectional bias and sexual harassment, students frequently witnessed or experienced microaggressions directed at their gender. One example of a gender-based microaggression towards female physicians was addressing women as 'Miss', or by their first name, as opposed to 'Doctor'. This was noted in comparison to male physicians, who are consistently introduced using their professional title.

...he would always refer to me as 'Miss' which is fine, but like I'm a doctor kind of respect it. T3

I was shadowing a group of [junior doctors] on the ward... they went in a pair to do a [clinical procedure]... the guy introduced himself as ' $\mathrm{Dr} \mathrm{X}$ ', then the woman using her first name... it felt a bit odd. P41

\section{Major theme 3: desired transformational change}

Participants spoke of initiatives to combat gender bias when considering the transformational change they perceived as necessary in striving for gender equity. Athena SWAN was mentioned as an intuitional initiative and praised for raising the profile of gender bias. Although faculty members possessed good awareness as to the aims of Athena SWAN, student participants were largely unaware of the initiative.

...that's where Athena SWAN is really good, because it's certainly raised the profile of gender. T9

Overall, however, Athena SWAN was seen as ineffectivea way of merely 'balancing the boardroom', without tackling the root of gender inequality or effecting cultural change.

I have been aware of deliberate moves to 'balance the boardroom' and make sure that women are at the table but that is meaningless and tokenistic if they are still subject to the same cultural negativity. T5

Athena SWAN has highlighted the issue, but the changes are trivial and meaningless. Institutions are playing the game to get the award, but it isn't a real cultural change. T8 
...things like ATHENA Swan tend to treat the symptoms rather than the problem. P20

Male faculty resented initiatives to 'balance the boardroom'. Borne of belief in the now refuted zero-sum labour market, men feared for their positions. This fear was framed as a desire for 'gender neutrality', without paying due heed to iniquitous conditions facilitating their initial advancement.

.... bias away from men and towards females... Athena SWAN...reinforces it doesn't it... it's put in higher prominence females...it probably makes a positive bias into making sure that everything is [balanced]... If you're a male coming through you.... will struggle... I personally think the best person should get the job, whatever their gender, we should have gender neutrality... T7

Female participants perceived such attitudes from men as a barrier to addressing gender bias.

I find that men in general don't want to talk about some things, they don't want to admit some things happened. P10

Despite a general unawareness of institutional initiatives to address gender bias, student participants spoke of the need to actively challenge gender imbalance in certain specialities. Suggestions included a minimum requirement of female trainees in recruitment processes.

...actively challenging it and saying we need to increase the numbers of female trainees; we need to set a minimum requirement. $\mathrm{P} 9$

Some participants drew on the negative expectations of women to motivate them to succeed. This was viewed as a personal way to redress gender bias. This motivation, however, falls in line with prove-it-again bias, and is not something men voiced experiencing.

I kind of feel spurred by the expectations people have against women in professional environments. That kind of motivates me. P4

\section{DISCUSSION}

This work reveals medical students perceive gender bias in multiple ways, aligned with William's patterns of bias. Maternal wall bias is a pattern fewer studies have explored but is gaining traction within medical research. Although overt discrimination for reasons of motherhood has decreased, implicit bias remains ever-present, systematically disadvantaging mothers in medicine. ${ }^{60}$ Within the USA, recent work by Halley et al, demonstrated the largescale clinical presence of implicit maternal bias, rooted in the masculine culture of medicine and manifesting as gendered job expectations, financial inequalities, work-life balance difficulties and restricted advancement opportunities for women. ${ }^{61}$ The UK landscape is largely similar, for example, the gender pay gap persists, with maternity leave implicated as one aetiological factor. ${ }^{4}$ Maternal wall bias is also documented within educational institutions. Female medical school faculty are less likely than men to feel belonging, and perceive lower gender equity. ${ }^{39}$ Participants noted poor representation of women in senior positions, paralleling previous research evidencing this deficiency. ${ }^{60}$ Women are more likely to assume educational roles within medical schools, with such teaching positions perceived as subordinate to management roles commonly assumed by men. ${ }^{60}$ This gender imbalance is akin to 'institutional housekeeping', where women accept greater administrative or teaching burden as a gendered job expectation, paralleling traditional roles in the home. ${ }^{62}$ Within this work, absence of women in senior institutional positions, and consequentially poor exposure to the paradigmatic trajectories of female leaders, propagated the myth that women are illsuited to lead. This supports previous research in demonstrating maternal wall bias and discrimination within medicine. ${ }^{63}$ As this work solicited the views of medical students, it has become clear that gender bias within medicine is overtly perceived by students both directly and indirectly. Through legitimate peripheral participation in a culture of bias (referred to as 'gendered communities of practice' by Samuriwo et $a l^{26}$ ), gender bias becomes part of students' educational experience clinically and institutionally. This work builds on previous research regarding gendered communities of practice and demonstrate the patterned ways in which students experience gender bias within these communities, most notably maternal wall bias.

In addition to demonstrating the patterns of bias that occur within communities of practice, this work demonstrates the influence of gendered experiences on students' professional identity development, a previously underexplored area that Volpe $e t$ al argue has rendered much research regarding professional identity biased in favour of white men. ${ }^{64}$ As paradigmatic trajectories within communities of practice 'embody the history of the community through the very participation and identities of practitioners, ${ }^{50}$ they also embody the gender bias entrenched within healthcare services. Hence, as students draw on these trajectories to form their identities within communities, gender bias plays a key role. In this study, gender bias manifested through poor access to paradigmatic trajectories female students felt able to identify with and the perception of women's trajectories as 'fraught', acting to dissuade female students from certain career aspirations. Exploring medical student specialty choice, Smith et al recently noted that women were more influenced than other genders by their 'connectedness' to a field in making career decisions. ${ }^{65}$ The manifestation of gender bias within a community of practice's paradigmatic trajectories offers an explanation for data by Smith et al-as education regarding the identities of a community takes place through 'seeing, hearing, doing and imagining ${ }^{5466}$ in regard to the career paths and identities 
paradigmatic trajectories make evident, students perceive connectedness to specialities where they can most easily imagine themselves moving through the field's available trajectories. ${ }^{66}$ When access to the paradigmatic trajectories of women is poor, or those trajectories are perceived as difficult, students struggle to imagine themselves in those roles, and may turn their aspirations elsewhere. This is one way in which gender bias operates within communities of practice. The suggestion of 'gendered communities of practice' by Samuriwo et al also applies here. Within gendered communities of practice, communities 'operate as sites of gendered activity', ${ }^{67}$ moulding participant identity. Those that do not conform to traditional gendered expectations within a community risk being pushed into marginalised learning trajectories, as opposed to accessing learning trajectories which would facilitate full participation within the community. ${ }^{67}$ Within medical education, the expectations propagated by communities of practice are similarly gendered, with students involved in a 'gendered apprenticeship' where, over time, gender bias is 'internalis(ed) and normalis (ed) ${ }^{26}$ In this way, students 'are... primed to perpetuate (gender bias)... when they become doctors' ${ }^{26}$ sustaining a culture of gender bias within medicine. This work adds to the findings by Samuriwo et al by suggesting paradigmatic trajectories as one mechanism within gendered communities of practice that manifest gender bias and subsequently shape student identities.

Medical students within this work also commented on the often-negative influence of their physical environments, which were noted as 'too male, too pale (and) too stale' regarding the imagery they displayed. Recent research into institutional historic portraiture's influence on medical students by Fitzsousa et al revealed students perceived such images as representing institutional values. ${ }^{68}$ In a setting where the visible portraits are invariably white men ${ }^{69}$ a message is sent that institutions value maleness, whiteness, elitism and power. ${ }^{68}$ In the study by Fitzsousa $e t a l$, this acted to negatively influence feelings of belonging among students who did not fit this traditional mould. ${ }^{68}$ This work acts to reinforce these early findings, on which there is little empirical data. To the authors' best knowledge, this is also the first UK work demonstrating how physical environments within medical institutions can act to propagate gender bias, demonstrating transferability of international findings.

Although this work corroborates previous findings that UK gender initiatives such as Athena SWAN have gone some way to raising the profile of gender equality, it acts in contravention to the bulk of previous work demonstrating significant impact of the initiative. ${ }^{70}$ This likely represents institutional variation regarding whether application of the initiative affects organisational culture change. Despite this work demonstrating significant gender bias, and perceptions that Athena SWAN is 'becoming an end in itself', a concern voiced by the research by Ovseiko $e t$ $a l^{70}$ animosity from some male faculty prevails regarding initiatives to eliminate bias. Concerns voiced by men include notions of moving towards an era of positive discrimination towards women, worry regarding their own position and progression and a desire for 'gender neutrality', where career decisions are based on merit alone. These views are problematic in several ways. First, positive discrimination-'(in the context of... employment)... the practice... of favouring individuals belonging to groups known to have been discriminated against previously, ${ }^{71}$-is illegal in the UK. However, male staff may have been trying to make reference to a dislike for positive action-'voluntary actions employers can take to address any imbalance of opportunity or disadvantage $^{, 72}$ - which is legal and widely practised. To illustrate this distinction, consider a woman applying for a job in a male-dominated field. It would be positive discrimination to employ the woman on the basis of gender alone rather than merit. Yet, an employer could take positive action in the form of outreach events or initiatives raising awareness of their field, possibilities and encouraging women to apply for the role. Previous research by Bryant et al demonstrated women are more likely to desire positive action on matters of gender, while men favour ideals of a 'meritocracy' with no one group given any further support. ${ }^{73}$ Yet, notions of meritocracy resemble a cultural myth. ${ }^{74}$ It simply is not true that so long as one is intelligent, principled and ambitious, they can succeed in medicine. The concept of meritocracy remains intrinsically linked to 'hierarchies of privilege'-hence, protected characteristics that fall outwith characteristics of the traditional medical patriarchy will be 'excluded from narratives of excellence' and act as barriers to success. ${ }^{74}$ Razack et al argue the notion of merit requires reformulation, so diversity in all its forms is valued, suggesting this may be achieved through improved engagement with the issues at hand and inclusive leadership. ${ }^{74}$

Finally, male faculty in this study voiced concern for their own careers in light of improved female career advancement. This view seems borne of belief in a zero-sum labour market, sometimes referred to in economic literature as the 'lump of labour' fallacy-the misconception a fixed amount of work (or 'lump of labour') exists. ${ }^{75} 76$ If believed, it seems natural to fear for your own job when witnessing the advancement of others. Yet, as the name suggests, this belief is not evidence based-as the economy grows through higher rates of employment, this creates more jobs, providing for both those already part of, and those entering, the medical education or medical labour market. ${ }^{75}$ In view of this, fears voiced by participants are unfounded cultural relics, rooted in flawed understandings of labour market dynamics and serving only to propagate bias. Given their coupling with a degree of animosity, these views can prove difficult to challenge, with communicators of this bias often difficult to engage. As Giles and Hill summarise, 'critiques of institutional culture can provoke strong dissonance among faculty... who hold stakes in an institution'.77 The first step of engagement involves actively challenging bias through awareness of its impact. ${ }^{78}$ As such, encouraging both faculty and student 
reflection regarding biases in a formal, guided manner is crucial and central to the endeavour of gender equity. ${ }^{79}$ Bias education programmes have been implemented in several medical schools internationally, with research citing positive outcomes. ${ }^{80-82}$ The implicit bias recognition framework by Sukhera and Watling provides a practical schema for integrating bias education within medical programmes for those currently without provision. ${ }^{83} 84$ Medical education would do well to mandate implicit bias training for both students and faculty, in line with an accepted model such as that by Sukhera and Watling. Those in senior roles must lead by example, actively reflecting and engaging with their own biases in a transparent way. Design and implementation of sponsorship programmes, encouraging men to advocate for the active promotion and success of their female sponsee, may also serve to engage more men in addressing gender bias and prevent feelings of disenfranchisement. ${ }^{785-88}$

\section{LIMITATIONS}

Although recruitment of this study was targeted nationally, and the perspective of students enrolled at multiple UK institutions are represented within our data, local recruitment via email at one institution elicited the largest proportion of study participants. This is an issue of access-ideally, all UK medical students would have been emailed invitations to participate, but restrictions of time, scope and institutional access prohibited this expansion. As such, the experiences presented in this work may best represent a single site, which may serve to limit result transferability. Although it could be argued some of the issues regarding gender bias reported here are institutionally specific, an intentionally large sample, triangulated using detailed faculty perspectives, was sought in an attempt to increase the transferability of reported findings and negate the unequal institutional spread of participants.

There is a greater predominance of female participants in our research (M:F 15:26). This may limit result transferability to male medical students however, given the nature of this study's research question and the increased prevalence of gender bias experiences among women, ${ }^{22}$ we believe the predominance of female participants in this research is likely to have added depth.

\section{CONCLUSION}

The aim of the present research was to explore medical student perceptions of gender bias within their medical education. Gender bias manifests in line with William's patterns of bias, identified within adjacent professional fields $^{48}$ and shapes students' professional identities through the mechanism of paradigmatic trajectories within gendered communities of practice. Gender bias within medicine, and bias directed at medical students, is also intersectional in nature, warranting further consideration and study. Despite initiatives, implicit bias persists within clinical and educational environments, overtly perceived by students and impacting career aspirations. Existing gender initiatives require scrutiny as this work identifies the superficial application of positive action, and a failure to affect meaningful change. It seems likely existing positive action does not go far enough to promote the advancement of women. The existence of flawed assumptions regarding a culture of meritocracy and labour market dynamics within male faculty may go some way to explain the superficial application and uptake of gender initiatives at this institution. Institutions should mandate participation in implicit bias education programmes for all staff, with regular review of progress. Physical environments manifest organisational values-as the imagery of these physical spaces remains 'too male, too pale, (and) too stale', medical students perceive implicit bias regarding which identities are most welcome in medicine. Institutions must strive to revise this imagery, so environments better represent present society. Overall, despite progress limiting overt gender discrimination, implicit gender bias persists pervasively. Future work should focus on studying the identified patterns of bias in more depth, in line with an intersectional approach. Gender initiatives, such as Athena SWAN, also require large-scale evaluation in regard to their impact on organisational culture, which this work found to be wanting.

Twitter Megan E L Brown @Megan_EL_Brown, George E G Hunt @geghunt and Gabrielle M Finn @gabs_finn

Contributors MELB, GEGH, FH and GMF contributed to the conception of the original research idea. GMF and MELB contributed knowledge of qualitative study design and study methodology. GEGH and FH conducted all data collection. All authors (MELB, GEGH, FH, GMF) were involved in data analysis and interpretation. All authors were involved in the drafting and the critical revision of the entire paper, approving the final manuscript for publication and have agreed to be accountable for all aspects of the work.

Funding The authors have not declared a specific grant for this research from any funding agency in the public, commercial or not-for-profit sectors.

Competing interests None declared.

Patient consent for publication Not required.

Ethics approval Institutional ethical approval was obtained from the Hull York Medical School, approval number 1816, prior to commencement of this research. Informed written consent was sought from all study participants prior to research commencement.

Provenance and peer review Not commissioned; externally peer reviewed.

Data availability statement As ethical approval was not obtained to make data sharing possible outside of the listed research team, no additional data are available.

Open access This is an open access article distributed in accordance with the Creative Commons Attribution Non Commercial (CC BY-NC 4.0) license, which permits others to distribute, remix, adapt, build upon this work non-commercially, and license their derivative works on different terms, provided the original work is properly cited, appropriate credit is given, any changes made indicated, and the use is non-commercial. See: http://creativecommons.org/licenses/by-nc/4.0/.

\section{ORCID iDs}

Megan E L Brown http://orcid.org/0000-0002-9334-0922

George E G Hunt http://orcid.org/0000-0002-6493-0915 


\section{REFERENCES}

1 European Institute for Gender Equity. Glossary and thesaurus: gender bias. Available: https://eige.europa.eu/

2 Deech R. Women doctors: making a difference. Report of the chair of the national working group on women in medicine. London: Department of Health, 2009.

3 Notzer N, Brown S. The feminization of the medical profession in Israel. Med Educ 1995;29:377-81.

4 Williams JC. The glass ceiling and the maternal wall in academia. New Direct High Educ 2005;2005:91-105.

5 Williams J. Measuring gender and women's empowerment using confirmatory factor analysis. Population program, institute of behavioural science. Boulder: University of Colorado, 2005.

6 Penny M, Jeffries R, Grant J, et al. Women and academic medicine: a review of the evidence on female representation. $J R$ Soc Med 2014;107:259-63.

7 Appleby J. The gender pay gap in the NHS. BMJ 2018;361:k1541.

8 Appleby J. Gender pay gap in England's NHS: little progress since last year. BMJ 2019;365:12089.

9 NHS England. Links between NHS staff experience and patient satisfaction: analysis of surveys from 2014 and 2015, 2018. Available: www.nhsstaffsurveys.com/Caches/Files/links-betweennhs-staff-experience-and-patient-satisfaction-1.pdf [Accessed Mar 2020].

10 The Lancet. Time's up for sexual harassment in medicine. Lancet 2018;391:2576.

11 Stone L, Phillips C, Douglas KA. Sexual assault and harassment of doctors, by doctors: a qualitative study. Med Educ 2019;53:833-43.

12 Nora LM, McLaughlin MA, Fosson SE, et al. Gender discrimination and sexual harassment in medical education: perspectives gained by a 14-school study. Acad Med 2002;77:1226-34.

13 National Academies of Sciences, Engineering, and Medicine. Sexual harassment of women: climate, culture, and consequences in academic sciences, engineering, and medicine. Washington DC: The National Academies Press, 2018.

14 Fitzpatrick S. A survey of staffing levels of medical clinical academics in UK medical schools as at 31 July 2011. London: Medical Schools Council, 2012.

15 Marsh JD, Chod R. Recruiting faculty leaders at U.S. medical schools: a process without improvement? Acad Med 2017;92:1564-8.

16 Munir F, Mason C, McDermott H, et al. Advancing women's careers in science, technology, engineering, mathematics and medicine: Evaluating the effectiveness and impact of the Athena SWAN charter. London: Equality Challenge Unit, 2013.

17 Donald A, Harvey PH, McLean AR. Bridging the gender gap in UK science. Nature 2011;478:36-8.

18 Schmidt E, Ovseiko P, Henderson L, et al. Understanding the athena SWAN award scheme for gender equality as a complex social intervention in a complex system: analysis of silver sward action plans in a comparative European perspective. Health Res Policy Systems 2020;18:1-21.

19 Athena SWAN Charter Independent Review Steering Group. The future of athena SWAN. Advance HE, 2020.

20 Brown JVE, Crampton PES, Finn GM, et al. From the sticky floor to the glass ceiling and everything in between: protocol for a systematic review of barriers and facilitators to clinical academic careers and interventions to address these, with a focus on gender inequality. Syst Rev 2020;9:26.

21 Stratton TD, McLaughlin MA, Witte FM, et al. Does students' exposure to gender discrimination and sexual harassment in medical school affect specialty choice and residency program selection? Acad Med 2005;80:400-8.

22 Witte FM, Stratton TD, Nora LM. Stories from the field: students' descriptions of gender discrimination and sexual harassment during medical school. Acad Med 2006;81:648-54.

23 Babaria P, Abedin S, Berg D, et al. "I'm too used to it": A longitudinal qualitative study of third year female medical students' experiences of gendered encounters in medical education. Soc Sci Med 2012;74:1013-20

24 Babaria P, Bernheim S, Nunez-Smith M. Gender and the pre-clinical experiences of female medical students: a taxonomy. Med Educ 2011;45:249-60.

25 Shaw M, Chandratilake M, Ho M, et al. Female victims and female perpetrators: medical students' narratives of gender dynamics and professionalism dilemmas. Adv Health Sci Educ 2019;20:1-21.

26 Samuriwo R, Patel Y, Webb K, et al. 'Man up': medical students' perceptions of gender and learning in clinical practice: a qualitative study. Med Educ 2020;54:150-61.

27 Sharma M. Applying feminist theory to medical education. Lancet 2019;393:570-8
28 Mann S, Ariyanayagam D. Gender bias in medical education: stop treating it as an inevitability. Med Educ 2020

29 Samuriwo R, Patel Y, Bullock A. Gender bias in medical education: stop treating it is an inevitability-Author reply. Med Educ 2020;54:150-61.

30 Williams J, Alon T, Bornstein S. Beyond the 'chilly climate': Eliminating bias against women. Thought \& Action 2006;79.

31 Berry LE. Creating community: strengthening education and practice partnerships through communities of practice. Int J Nurs Educ Scholarsh 2011;8.

32 Gonzalo JD, Thompson BM, Haidet P, et al. A constructive reframing of student roles and systems learning in medical education using a communities of practice lens. Acad Med 2017;92:1687-94.

33 Ranmuthugala G, Plumb JJ, Cunningham FC, et al. How and why are communities of practice established in the healthcare sector? A systematic review of the literature. BMC Health Serv Res 2011;11:273.

34 Tsouroufli M, Rees CE, Monrouxe LV, et al. Gender, identities and intersectionality in medical education research. Med Educ 2011:45:213-6.

35 Cassell C, Symon G. Promoting new research practices in organisational research. In: Cassell C, Symon G, eds. Essential guide to qualitative methods in organisational research. London: Sage, 2004.

36 Schwandt T. Three epistemological stances for qualitative inquiry: interpretativism, hermeneutics and social constructionism. In: Denzin N, Lincoln Y, eds. The landscape of qualitative research: theories and issues. Thousand Oaks: Sage, 2003: 292-331.

37 Rees CE, Crampton PES, Monrouxe LV. Re-visioning academic medicine through a constructionist lens. Acad Med 2020;95:846-50.

38 Young RA, Collin A. Introduction: constructivism and social constructionism in the career field. J Vocat Behav 2004;64:373-88.

39 Pololi LH, Civian JT, Brennan RT, et al. Experiencing the culture of academic medicine: gender matters, a national study. J Gen Intern Med 2013;28:201-7.

40 Fernando W. A social constructionist perspective of gender stereotyping at work: a case of highly skilled women in Sri Lanka. Gender Manage 2012;27:463-81.

41 Eppich WJ, Dornan T, Rethans J-J, et al. "Learning the lingo": a grounded theory study of telephone talk in clinical education. Acad Med 2019;94:1033-9.

42 Walker D, Myrick F. Grounded theory: an exploration of process and procedure. Qual Health Res 2006;16:547-59.

43 Maz J. Employing a grounded theory approach: core characteristics. Bri J Cardiac Nur 2013;8:453-8.

44 Charmaz K. Constructing grounded theory. London: Sage Publications, 2006.

45 Varpio L, Ajjawi R, Monrouxe LV, et al. Shedding the cobra effect: problematising thematic emergence, triangulation, saturation and member checking. Med Educ 2017;51:40-50.

46 Monrouxe LV. When I say... intersectionality in medical education research. Med Educ 2015;49:21-2.

47 Denis A. Review essay: intersectional analysis: a contribution of feminism to sociology. Inter Sociol 2008;23:677-94.

48 Williams J, Dempsey R, Slaughter A. What works for women at work: four patterns working women need to know. NYU Press, 2014.

49 Lave J, Wenger E. Situated learning: legitimate peripheral participation. Cambridge university press, 1991.

50 Wenger E. Communities of practice: learning, meaning, and identity. Cambridge university press, 1999.

51 Wenger E. Communities of practice: a brief introduction, 2006. Available: http://ewenger.com/ [Accessed Jan 2020].

$52 \operatorname{Cox}$ A. What are communities of practice? a comparative review of four seminal works. J Inf Sci 2005;31:527-40.

53 Hay K. Legitimate peripheral participation, instructionism, and constructivism: whose situation is it anyway. Educ Tech 1993;33:33-8.

54 Hill E, Vaughan S. The only girl in the room: how paradigmatic trajectories deter female students from surgical careers. Med Educ 2013;47:547-56.

55 Charmaz K. Constructing grounded theory. 2nd ed. Thousand Oaks: Sage, 2014.

56 Morse J. Situating grounded theory within qualitative inquiry. In: Schreiber R, Stern P, eds. Using grounded theory in nursing. New York: Springer Publishing Company, 2001: 1-16.

57 Noble H, Mitchell G. What is grounded theory? Evid Based Nurs 2016;19:34-5.

58 Varpio LM, Mylopoulos MM. Qualitative research methodologies: embracing methodological borrowing, shifting and importing. In: Cleland J, Durning S, eds. Researching medical education. Wiley, Blackwell, 2015. 
59 Watling CJ, Lingard L. Grounded theory in medical education research: AMEE guide No. 70. Med Teach 2012;34:850-61.

60 Farid H. Hidden costs of motherhood in medicine. Obstet Gynecol 2019;134:1339-41.

61 Halley MC, Rustagi AS, Torres JS, et al. Physician mothers' experience of workplace discrimination: a qualitative analysis. BMJ 2018;173:k4926.

62 Bird S, Litt J, Wang Y. Creating status of women reports: institutional housekeeping as women's work. NWSA Journal 2004:194-206.

63 Ju M, van Schaik SM. Effect of professional background and gender on residents' perceptions of leadership. Acad Med 2019;94:S42-7.

64 Volpe RL, Hopkins M, Haidet P, et al. Is research on professional identity formation biased? early insights from a scoping review and metasynthesis. Med Educ 2019;53:119-32.

65 Smith V, Bethune C, Hurley KF. Examining medical student specialty choice through a gender lens: an orientational qualitative study. Teach Learn Med 2018;30:33-44.

66 Brown ME, Laughey W, Finn GM. Physician associate students and primary care paradigmatic trajectories: perceptions, positioning and the process of pursuit. Educ Prim Care 2020;23:1-9.

67 Atencio M, Koca C. Gendered communities of practice and the construction of masculinities in Turkish physical education. Gend Educ 2011;23:59-72.

68 Fitzsousa E, Anderson N, Reisman A. "This institution was never meant for me": the impact of institutional historical portraiture on medical students. J Gen Intern Med 2019;34:2738-9.

69 Wellbery $\mathrm{C}$, Mishori R. Deck the halls with diverse portraits. JAMA 2018;320:528-30.

70 Ovseiko PV, Chapple A, Edmunds LD, et al. Advancing gender equality through the Athena Swan charter for women in science: an exploratory study of women's and men's perceptions. Health Res Policy Syst 2017;15:12.

71 Oxford University Press. Oxford English dictionary, 2012.

72 NHS Employers. What is positive action? 2018. Available: https:// www.nhsemployers.org/your-workforce/plan/recruiting-from-yourcommunity/positive-action/what-is-positive-action [Accessed Mar 2020].

73 Bryant LD, Burkinshaw P, House AO, et al. Good practice or positive action? using $Q$ methodology to identify competing views on improving gender equality in academic medicine. BMJ Open 2017;7:e015973.

74 Razack S, Risør T, Hodges B, et al. Beyond the cultural myth of medical meritocracy. Med Educ 2020;54:46-53.

75 Walker T. The "lump-of-labor" case against work-sharing: populist fallacy or marginalist throwback? In: Golden L, Figart D, eds. Working time: international trends, theory and policy perspectives. Routledge, 2000.

76 Schloss D. Why working men dislike piece work. Economic Rev 1891:1:311-26.

77 Giles JA, Hill EJR. Examining our hidden curricula: powerful, visible, gendered and discriminatory. Med Educ 2015;49:244-6.

78 DiBrito SR, Lopez CM, Jones C, et al. Reducing implicit bias: association of women surgeons \#HeForShe task force best practice recommendations. J Am Coll Surg 2019;228:303-9.

79 Westring A, McDonald JM, Carr P, et al. An integrated framework for gender equity in academic medicine. Acad Med 2016;91:1041-4.

80 Wainer J. Gender and the medical curriculum: a rural case study. Women Health 2003;37:67-87.

81 Rogers N, Henrich J. Teaching women's health into the 21st century. Women Health 2003;37:11-21.

82 Poustchi Y, Saks NS, Piasecki AK, et al. Brief intervention effective in reducing weight bias in medical students. Fam Med 2013;45:345.

83 Sukhera J, Watling C. A framework for integrating implicit bias recognition into health professions education. Acad Med 2018;93:35-40.

84 Sukhera J, Watling CJ, Gonzalez CM. Implicit bias in health professions: from recognition to transformation. Acad Med 2020;95:717-23.

85 Watson E. Gender equality is your issue too. speech by un women goodwill Ambassador Emma Watson at a special event for the HeForShe campaign. New York: United Nations Headquarters, 2014.

86 Hemphill ME, Maher Z, Ross HM. Addressing gender-related implicit bias in surgical resident physician education: a set of guidelines. $J$ Surg Educ 2020;77:491-4.

87 Rabinowitz LG. Recognizing blind spots - a remedy for gender bias in medicine? N Engl J Med 2018;378:2253-5.

88 Hughes F, Bernstein PS. Sexism in obstetrics and gynecology: not just a "women's issue". Am J Obstet Gynecol 2018;219:364.e1-e4. 